\title{
Importance of a distal proximal contact on load transfer by implant-supported single adjacent crowns in posterior region of the mandible: a photoelastic study
}

\author{
Fábio Afrânio de AGUIAR JÚNIOR, Rodrigo TIOSSI, Ana Paula MACEDO, Maria da Gloria Chiarello de MATTOS, \\ Ricardo Faria RIBEIRO, Renata Cristina Silveira RODRIGUES
}

Department of Dental Materials and Prosthodontics, School of Dentistry of Ribeirão Preto, University of São Paulo, Ribeirão Preto, SP, Brazil.

Corresponding address: Renata C. S. Rodrigues - Faculdade de Odontologia de Ribeirão Preto - Universidade de São Paulo - Departamento de Materiais Dentários e Prótese - Av. do Café, s/n - Monte Alegre - Ribeirão Preto - SP - Brasil - 14040-904 - Phone: +55 (16) $3602-4005$ - Fax: +55 (16) $3633-0999$ e-mail: renata@forp.usp.br

Submitted: January 10, 2013 - Modification: April 29, 2013 - Accepted: July 4, 2013

ABSTRACT

bjective: This study aimed to evaluate the importance of a distal proximal contact
on the load transfer to the posterior region of the mandible by non-splinted adjacent
implant-supported crowns using photoelastic stress analysis. Material and Methods: A
rectangular model ( $68 \times 30 \times 15 \mathrm{~mm}$ ) was made of polymethylmethacrylate resin to simulate
half of the mandibular arch. One model was completed with resin replicas representing
the first premolar and second molar and with two $3.75 \mathrm{~mm}$ dia. $\times 11 \mathrm{~mm}$ internal hexagon
threaded implants replacing the second premolar and first molar. The other model was
manufactured in the same way but without the second molar. Both models were duplicated
using photoelastic resin. The roots of the teeth replicas were covered with a layer of
polyether impression material to simulate the periodontal ligament. Two different vertical
loads were applied to the crowns as follows: 1 - single static point load alternately applied
to the crowns replacing the second premolar and first molar $(50 \mathrm{~N}) ; 2-$ simultaneous static
point loads applied to both of the crowns replacing the second premolar and first molar
$(100 \mathrm{~N})$. The resulting isochromatic fringe pattern in the photoelastic model was monitored
and photographed. Results: All loading conditions studied showed that the presence of the
second molar has changed the load transmission and the pattern of stresses. Conclusion:
Results showed that the presence of a second molar proximal contact can help minimize
the stresses around the implants.

Keywords: Fixed partial denture. Dental implants. Implant-supported dental prosthesis. Dental stress analysis.

\section{INTRODUCTION}

Despite the increased use of osseointegrated implants and the high levels of success associated with the restoration of edentulous spaces $7,9,28$, the rehabilitation of a posterior edentulous space still is a challenging biomechanical condition. Mechanical and biological factors are involved in the long-term success of an implant-supported rehabilitation and several options are available for the restoration of a partial posterior edentulous space; however, there is no consensus in literature as to which would be the best prosthetic solution to be used $5,20,25,30$. The success of dental implants has challenged the doctrine that the extraction of a teeth should be considered undesirable ${ }^{13}$. According to Zitzman, et al. ${ }^{31}$ (2010), some authors consider that the implant is a better and more reliable abutment than the tooth itself and propose the extraction of even salvageable teeth.

Splinting or not splinting multiple adjacent crowns is a matter of concern. Some authors suggest that splinting multiple implants together could better distribute the functional loads and 
provide higher maintenance of the marginal bone levels ${ }^{19,22,24}$. However, restoration with multiple single implants minimizes the loosening or fracture of components under functional loads $^{11}$. Other advantages of using non-splinted prostheses are the better esthetic outcome and more passive-fitting frameworks ${ }^{16,19}$. The characteristics of the proximal contacts are more critical for better passivity and transmission of loads because non-ideal contacts might lead to increased stresses around the implants due to the absence of the periodontal ligament (PDL) on the implants ${ }^{11}$. Without the information provided by the mechanoreceptors that are present in the $\mathrm{PDL}$, the fine motor control of the mandible will be impaired. A balanced occlusal relationship is thus critical for the long-term survival of implantsupported prostheses ${ }^{13}$.

The influence of a proximal contact on the force transfer in implant-prostheses is rarely discussed within literature. Further knowledge about this issue may allow better planning of implant-supported prostheses. This study aims to evaluate the influence of a distal molar proximal contact and different loading by occlusal contacts on the load and stress distributions around implants in the posterior region of the mandible using photoelasticity. The null hypothesis was that the stress pattern and the stress distribution generated by loading adjacent non-splinted screw-retained metal-ceramic crowns would not be affected by the absence of the second molar distal contact.

\section{MATERIAL AND METHODS}

A rectangular model $(68 \times 30 \times 15 \mathrm{~mm})$ was made of polymethylmethacrylate (PMMA) resin (Plexiglas ${ }^{\circledR}$, Altuglas International, Philadelphia, Pennsylvania, USA) to simulate half of the mandibular arch. The model was completed with resin replicas (Odontofix, Ribeirão Preto, $S P$, Brazil) representing the first premolar and second molar, and with two $3.75 \mathrm{~mm}$ dia. $\mathrm{x} 11 \mathrm{~mm}$ internal hexagon threaded implants (Titamax II Plus, Neodent ${ }^{\circledR}$, Curitiba, PR, Brazil) replacing the second premolar and first molar. The preparation of the PMMA resin for positioning the teeth and implants was made in an optimal mesiodistal position, allowing the rehabilitation with two implant-supported crowns with acceptable anatomy proportional to that of the replaced teeth.

The crowns were waxed on UCLA prosthetic components (UCLA II Plus Tilite, Neodent ${ }^{\circledR}$, Curitiba, PR, Brazil) that were screwed to the implants with a $20 \mathrm{~N} . \mathrm{cm}$ torque, as recommended by the manufacturer. The wax patterns were reduced to allow for the adequate shape of ceramic-veneered metal frameworks. The metal frameworks were cast in nickel-chromiumtitanium alloy (Tilite Omega, Talladium Inc, Valencia, California, USA). A silicone (Zetalabor, Zhermack S.p.A., Rovigo, Veneto, Italy) index was made from the initial wax pattern to standardize the application of the esthetic veneers and the final anatomy of the crowns.

The crowns were veneered with IPS d.Sign ceramic (Ivoclar Vivadent, Schaan, Liechtenstein) in accordance to recommendations from the manufacturer. The crowns were then placed on the master model and the effectiveness of the proximal contacts was checked using a $21 \mu \mathrm{m}$ thick double-sided occlusal marking film (AccuFilm II, Parkell Inc., Edgewood, New York, USA) and dental floss (Colgate-Palmolive, São Bernardo do Campo, SP, Brazil), according to clinically accepted procedures that would result in light contact tightness ${ }^{11}$.

To fabricate the photoelastic model, a silicone mold (Silicone Master, Talmax, Curitiba, PR, Brazil) was made of the initial model to correctly transfer the position of the teeth and implants. The roots of teeth replicas were covered with a layer of polyether impression material (Impregum Soft, 3M ESPE AG, Seefeld, Bavaria, Germany) to simulate the periodontal ligament $21,26,30$. The implants were directly embedded in the photoelastic model without any interposed material thus assuming complete osseointegration. Teeth replicas and implants were positioned in the silicone mold before the manipulation and pouring of the photoelastic resin (Araldite GY279 and hardener Aradur 2963, Huntsman, Everberg, Belgium). Another similar photoelastic model was made, differing from the first model due to the absence of the second molar resin replica.

A polariscope (PS-100 SF Standard Field Polarimeter, Strainoptics, Inc., North Wales, Pennsylvania, USA) was used to monitor the isochromatic fringes and a digital camera (EOS Rebel, Canon, Tokyo, Japan) was coupled to the polariscope to photograph each load sequence. A load application device was developed at the Department of Dental Materials and Prosthodontics of the Ribeirão Preto School of Dentistry University of São Paulo (FORP/USP) using a $500 \mathrm{~N}$ load cell (Kratos Industrial Equipments, Cotia, SP, Brazil) and a digital load reader (IKE-01, Kratos Industrial Equipments). Two different loads were applied for each prosthetic configuration: 1 single static point load alternately applied to the crowns replacing the second premolar and first molar (50 N); 2 - static point loads simultaneously applied to both of the crowns replacing the second premolar and first molar $(100 \mathrm{~N})$. The vertical 
loads were applied to the crowns in an off-axis position: dislodged from the center of the implants on the distal fossa of the first molar $(3.9 \mathrm{~mm})$ and mesial fossa of the second premolar $(2.4 \mathrm{~mm})$. The load was perpendicular to the occlusal plane.

The photoelastic model was inspected inside the field of the circular polariscope to certify the absence of any residual stress before placing the crowns and before any load was applied. The crowns were then tightened to the implants with a $20 \mathrm{~N} . \mathrm{cm}$ torque and the experimental loads were applied. After each load application and before the next load, the photoelastic model was submitted to thermal stress relaxation. The model was placed for 10 minutes in an incubator set at $50^{\circ} \mathrm{C}$. After removal from the incubator, the photoelastic model was allowed to cool at $\sim 22^{\circ} \mathrm{C}$ for another 10 minutes and then checked in the polariscope for absence of any residual stresses. No apparent distortion of the model was detected after this procedure and, according to the manufacturer, the material has a flash point above $200^{\circ} \mathrm{C}$.

For the qualitative analysis, the model was positioned in the polariscope adjusted to circular polarization mode. For the quantitative analysis, the polariscope was then adjusted to plane polarization mode, and a $10 \mathrm{X}$ magnification lens (Nikon, Tokyo, Japan) was coupled to the set. Five points of interest were considered for this analysis: three in the cervical region of the implants, near to the simulated crestal bone and teeth, and one in the apical region of each implant (Figure 1). In all models, the points of interest were standardized in the same positions using an acrylic template.

Quantification of the fringe orders $(\mathrm{N})$ was made using the Senarmont method ${ }^{17,18}$. The optical constant $(K)$ of the photoelastic resin (3.57 Brewsters) was previously determined through a diametral compression test of a disc $(30 \times 10 \mathrm{~mm})$ fabricated specifically for the test. Principal stresses $(\sigma)$ in MPa for each point were calculated using the stress-optical law equation: $\sigma=(N . \lambda) /(b . K)$. The wavelength $(\lambda)$ of light passing through the photoelastic resin was $570 \mathrm{~nm}$, the photoelastic model thickness (b) was $15 \mathrm{~mm}, \mathrm{~K}$ was the optical constant of the photoelastic resin determined for the study (3.57 Brewsters), and $\mathrm{N}$ was the value of the fringe order at each point of interest ${ }^{8}$.

\section{RESULTS}

After the single point load on the first molar (Figures 2 and 3 ), the two experimental conditions (with and without the second molar) presented concentrating stresses around the first molar replacing implant, near the apical and distal regions of the implant. This finding shows that load application in the distal portion of the first molar crown leads to a small distal cantilever extension, thus leading to higher stresses in the distal region as opposed to the mesial region. The presence of the second molar distal contact reduced the stress transmission to the supporting structures (Figure 2). When compared with the missing molar condition (Figure 3 ), stresses in the distal region of the model were reduced from $15.75 \mathrm{MPa}$ to 6.28 MPa and from $5.53 \mathrm{MPa}$ to $1.38 \mathrm{MPa}$ in the region between the implants (Table 1 ).

When simultaneous loads were applied on the implants replacing the second premolar and first molar (Figure 4, Figure 5), higher stresses were found when compared to the single point loads. The application of an off-axis load is then evidenced and concentrating stresses were found at the points of interest 1 and 4 (Table 1 ). The presence of the second molar again reduced the stress distribution (Figure 4).

For the groups with a single point load applied on the implant replacing the second premolar

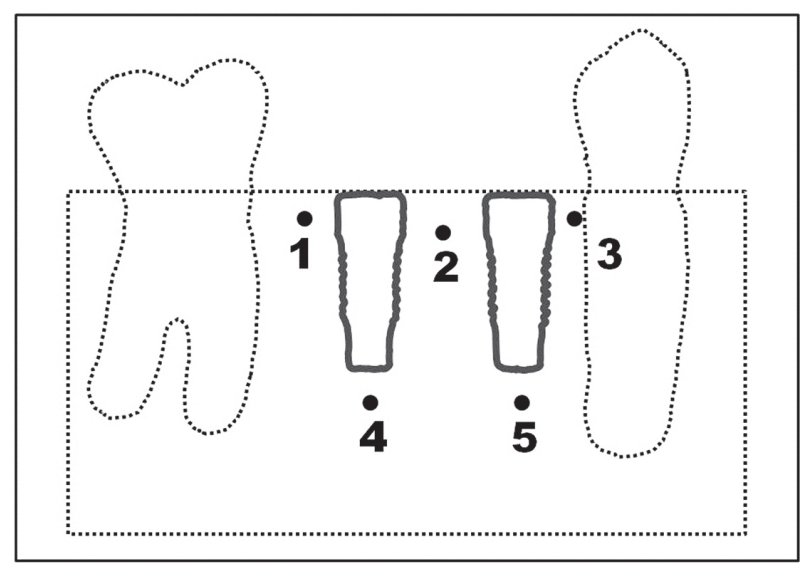

Figure 1- Points of interest selected for the quantitative analysis

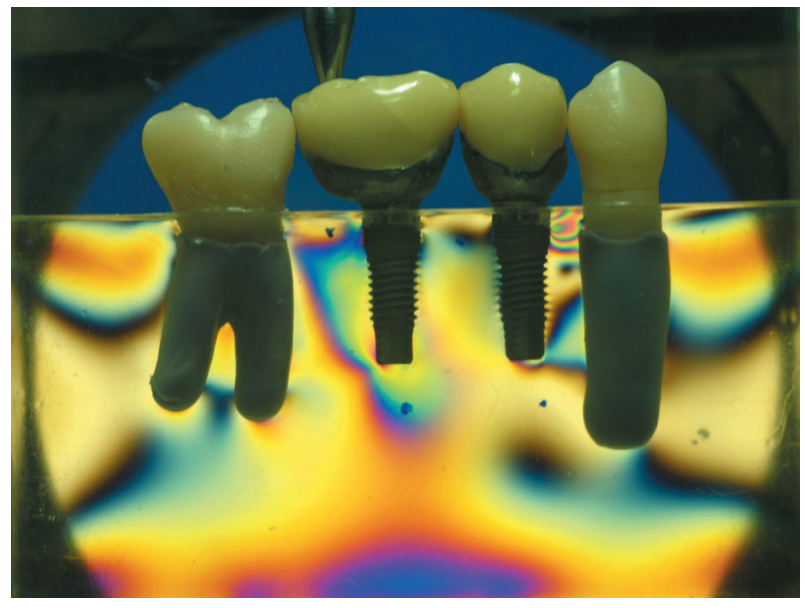

Figure 2- Vertical single point load (5 kgf) on the first molar (model with the second molar replica) 
(Figures 6 and 7), concentrating stresses were found around the loaded implant in both models analyzed (with and without the second molar). When the second molar replica was present, its combination with the first molar-replacing implant was more effective for load distribution (Figure 6). Stresses were concentrated around the second molar-replacing implant when the second molar distal contact was absent (Figure 7).

Table 1- Principal stresses (MPa) in the selected points of interest

\begin{tabular}{cccccccc}
\hline $\begin{array}{c}\text { Points of } \\
\text { interest }\end{array}$ & \multicolumn{3}{c}{ With $2^{\text {nd }}$ molar } & \multicolumn{3}{c}{${\text { Without } 2^{\text {nd }} \text { molar }}^{\text {Location of the load application }}$} & \multicolumn{3}{c}{ Location of the load application } \\
\hline & Molar & Simultaneous & Premolar & Molar & Simultaneous & Premolar \\
\hline 1 & 6.28 & 8.83 & 6.17 & 15.75 & 10.54 & 2.66 \\
\hline 2 & 1.38 & 7.13 & 10.11 & 5.53 & 4.58 & 7.77 \\
\hline 3 & 26.93 & 22.99 & 25.33 & 11.07 & 20.01 & 10.54 \\
\hline 4 & 15.65 & 15.43 & 4.15 & 8.2 & 13.73 & 4.47 \\
\hline 5 & 4.04 & 3.51 & 2.77 & 3.09 & 2.43 & 3.62 \\
\hline
\end{tabular}

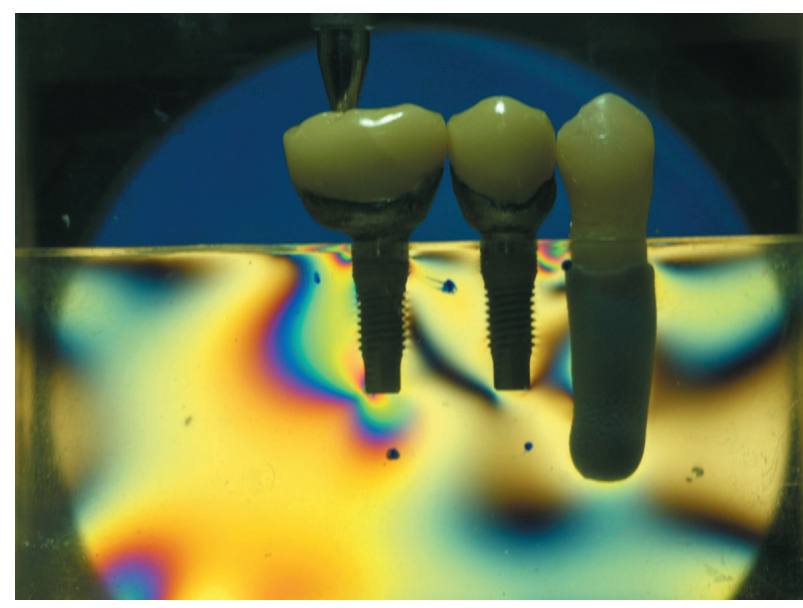

Figure 3- Vertical single point load (5 kgf) on the first molar (model without the second molar replica)

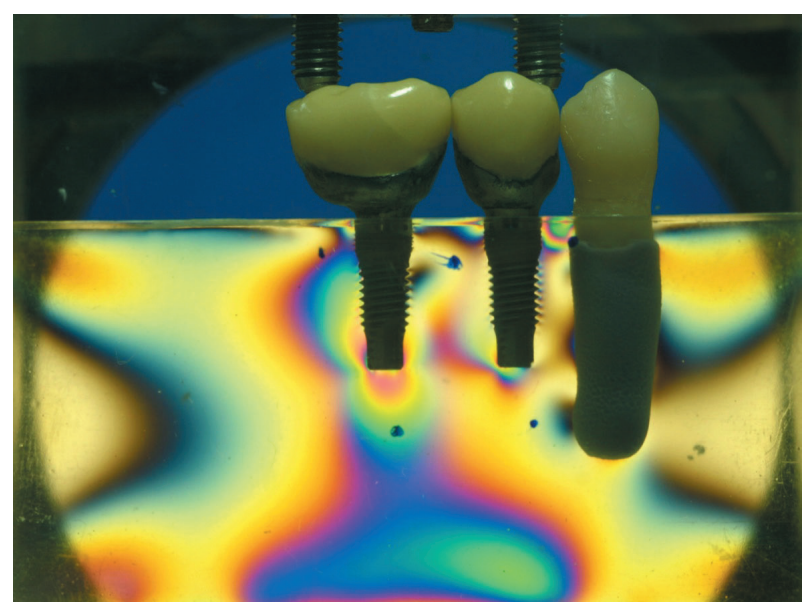

Figure 5- Simultaneous point load (10 kgf) on the second premolar and first molar (model without the second molar replica)

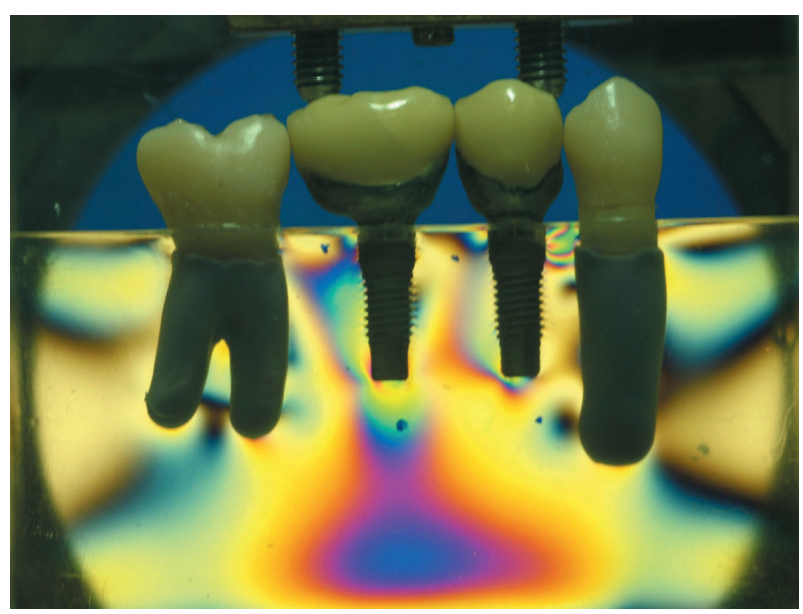

Figure 4- Simultaneous point load (10 kgf) on the second premolar and first molar (model with the second molar replica)

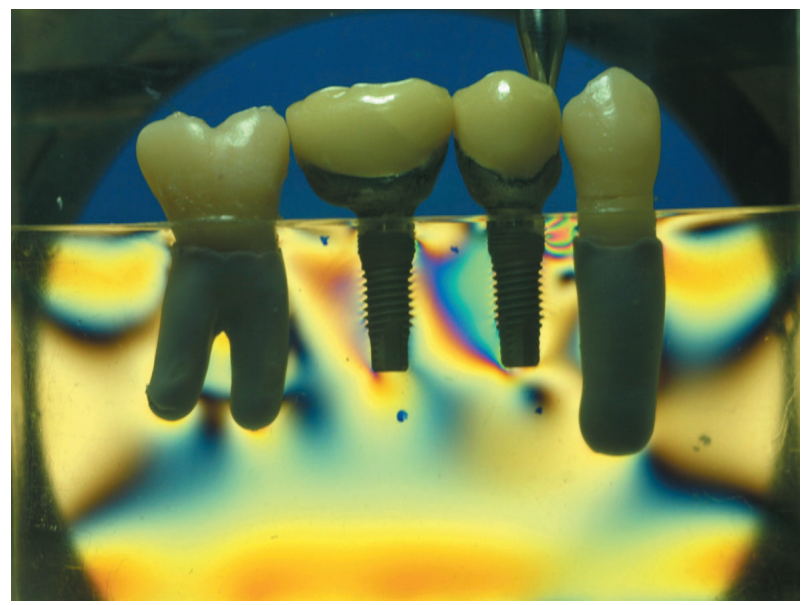

Figure 6- Vertical single point load (5 kgf) on the second premolar (model with the second molar replica) 


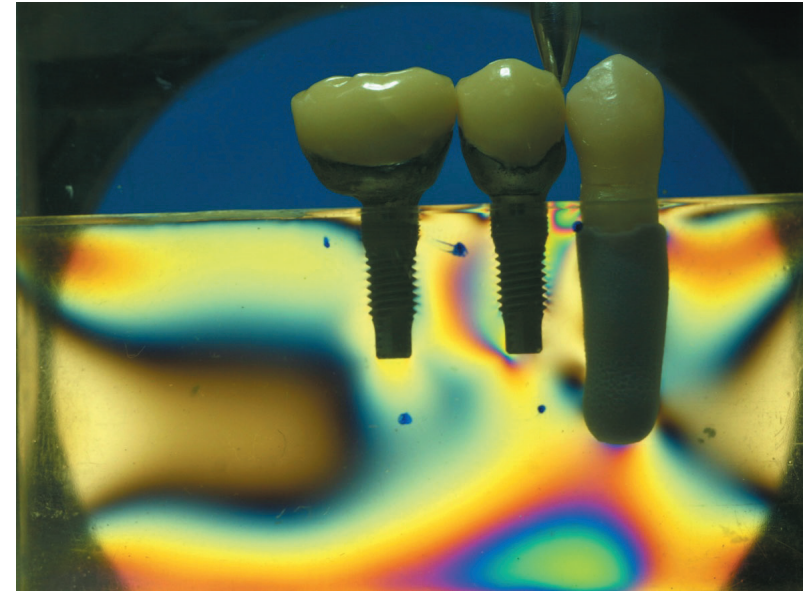

Figure 7- Vertical single point load (5 kgf) on the second premolar (model without the second molar replica)

\section{DISCUSSION}

The results found in this study suggest that the presence of a second molar distal to an edentulous space restored by implant-supported single crowns reduces the stresses in the supporting simulating-bone structure under different loading conditions. The presence of an effective proximal contact influenced the stress pattern and load distribution to the implant. This finding is in agreement with another study ${ }^{11}$, where a relation between interproximal contact tightness increase and higher stresses were noted. The off-axis load application points on the crowns, especially in the distal fossa of the first molar, led to a small cantilever extension, thus showing the importance of the contact points in distributing the stresses. It was also evident that the absence of the second molar leads to stress concentration in the distal region of the model.

Some clinicians have a preference for restoring an edentulous space with multiple adjacent single crowns rather than with splinted adjacent crowns, due to an easier control of hygiene, better passivity, more comfort to the patient and easier repair $^{14,19,24}$. However, single implants placed in posterior regions (premolar and molar regions) are more prone to non-axial overload ${ }^{1}$.

Photoelasticity is a well-documented method that has been used in dentistry ${ }^{3,23}$ and provides correspondence between experimental results and clinical findings ${ }^{4,10,15}$. It should be stated that one of the main limitations of this study is related to the selection of the points of interest, which must be chosen before load application. This could lead to the selection of a point of interest outside a region with higher stress concentration found by the qualitative analysis. Another limitation is related to the non differentiaton between cortical and cancellous bones. However, it should be pointed that the stress magnitudes may be modified, but the location of the stress concentration does not change substantially? Despite the differences between the photoelastic models and the clinical situation, the results found by photoelasticity can usefully assess the stress patterns and the load distribution, enabling the detection of stress-related difficulties that may arise ${ }^{23}$. Considering the multiple options available to restore an edentulous space, the understanding of the biomechanics of stress transmission of single crowns supported by multiple adjacent implants is critical to achieve a long-term clinical outcome.

This study simulated occlusal loads that do not correspond to the condition of a balanced and well-adjusted occlusion and showed increased stresses in some regions $6,13,25,27$. When more unfavorable bone conditions are present, and the use of longer or wider implants is limited, the differences found in this study may be even more clinically significant for the long-term success of an implant-supported rehabilitation 2,12,29. Longterm longitudinal clinical studies are still needed to assess and to understand the biomechanics of implant-supported prostheses and the actual influence that the induced stresses have on the success of the restorative treatment.

\section{CONCLUSION}

Within the limitations of the methodology used in this study and according to the results found, it can be concluded that the presence of a second molar proximal contact is important in minimizing the stresses around implants supporting metalceramic single crowns, irrespective of the occlusal loading condition. This conclusion indicates that the null hypothesis of this study should be rejected. Thus, if there is a healthy or treatable tooth in the posterior edentulous space that could be maintained, this must be evaluated as an important option for the treatment.

\section{ACKNOWLEDGEMENTS}

This study was supported by research grant \#2008/06960-8 from FAPESP - São Paulo Research Foundation. 


\section{REFERENCES}

1- Abboud M, Koeck B, Stark H, Wahl G, Paillon R. Immediate loading of single-tooth implants in the posterior region. Int J Oral Maxillofac Implants. 2005;20:61-8.

2- Akça K, Cehreli MC. A photoelastic and strain-gauge analysis of interface force transmission of internal-cone implants. Int $]$ Periodontics Restorative Dent. 2008;28:391-9.

3- Assunção WG, Barão VA, Tabata LF, Gomes EA, Delben JA, Santos PH. Biomechanics studies in dentistry: bioengineering applied in oral implantology. J Craniofac Surg. 2009;20:1173-7. 4- Brodsky JF, Caputo AA, Furstman LL. Root tipping: a photoelastic-histopathologic correlation. Am J Orthod. 1975;67:110.

5- Brunski J.B. In vivo bone response to biomechanical loading at the bone/dental-implant interface. Adv Dent Res. 1999;13:99-119. 6- Carr AB, Gerard DA, Larsen PE. The response of bone in primates around unloaded dental implants supporting prostheses with different levels of fit. J Prosthet Dent. 1996;76:500-9.

7- Celik G, Uludag B. Photoelastic stress analysis of various retention mechanisms on 3-implant-retained mandibular overdentures. J Prosthet Dent. 2007;97:229-35.

8- Dally JW, Riley WF (eds). Experimental stress analysis. New York: McGraw-Hill; 1978.

9- Grandi T, Garuti G, Guazzi P, Tarabini L, Forabosco A. Survival and success rates of immediately and early loaded implants: 12-month results from a multicentric randomized clinical study. J Oral Implantol. 2012;38:239-49.

10- Gross MD, Nissan J. Stress distribution around maxillary implants in anatomic photoelastic models of varying geometry. Part II. J Prosthet Dent. 2001;85:450-4.

11- Guichet DL, Yoshinobu D, Caputo AA. Effect of splinting and interproximal contact tightness on load transfer by implant restorations. J Prosthet Dent. 2002;87:528-35.

12- Holmes DC, Loftus JT. Influence of bone quality on stress distribution for endosseous implants. J Oral Implantol. 1997; $23: 104-11$.

13- John V, Chen S, Parashos P. Implant or the natural tooth - a contemporary treatment planning dilemma? Aust Dent $\mathrm{J}$. 2007;52:S138-50.

14- Kan JY, Rungcharassaeng K, Bohsali K, Goodacre CJ, Lang BR. Clinical methods for evaluating implant framework fit. J Prosthet Dent. 1999;81:7-13.

15- Kim WD, Jacobson Z, Nathanson D. In vitro stress analyses of dental implants supporting screw-retained and cement-retained prostheses. Implant Dent. 1999;8:141-51.

16- Kregzde M. A method of selecting the best implant prosthesis design option using three-dimensional finite element analysis. Int J Oral Maxillofac Implants. 1993;8:662-73.
17- Montarou CC, Gaylord TK. Two-wave-plate compensator method for single-point retardation measurements. Appl Opt. 2004;43:6580-95.

18- Nagib NN. New formulas for phase retardance measurements of birefringent plates. Opt Laser Technol. 1999;31:309-13.

19- Norton MR. Multiple single-tooth implant restorations in the posterior jaws: maintenance of marginal bone levels with reference to the implant-abutment microgap. Int J Oral Maxillofac Implants. 2006;21:777-84.

20- Papavasiliou G, Kamposiora P, Bayne SC, Felton DA. Threedimensional finite element analysis of stress-distribution around single tooth implants as a function of bony support, prosthesis type, and loading during function. J Prosthet Dent. 1996;76:63340.

21- Rabitz, GK, Berson R, Caputo AA, Franklin RJ, Del Fierro DB. Load-induced stresses in photoelastic primary canines with facial restorations. J Dent Child (Chic). 2006;73:170-4.

22- Rangert BR, Sullivan RM, Jemt TM. Load factor control for implants in the posterior partially edentulous segment. Int J Oral Maxillofac Implants. 1997;12:360-70.

23- Sadowsky SJ, Caputo AA. Effect of anchorage systems and extension base contact on load transfer with mandibular implantretained overdentures. J Prosthet Dent. 2000;84:327-34.

24- Simon RL. Single implant-supported molar and premolar crowns: a ten-year retrospective clinical report. J Prosthet Dent. 2003;90:517-21.

25- Skalak R. Biomechanical considerations in osseointegrated prostheses. J Prosthet Dent. 1983;49:843-8.

26- Soares CJ, Martins LR, Fonseca RB, Correr-Sobrinho L, Fernandes Neto $A J$. Influence of cavity preparation design on fracture resistance of posterior Leucite-reinforced ceramic restorations. J Prosthet Dent. 2006;95:421-9.

27- Sones AD. Complications with osseointegrated implants. J Prosthet Dent. 1989;62:581-5.

28- Srinivasan M, Padmanabhan TV. Intrusion in implant-toothsupported fixed prosthesis: an in vitro photoelastic stress analysis. Indian J Dent Res. 2008;19:6-11.

29- Tada S, Stegaroiu R, Kitamura E, Miyakawa O, Kusakari H. Influence of implant design and bone quality on stress/strain distribution in bone around implants: a 3-dimensional finite element analysis. Int J Oral Maxillofac Implants. 2003;18:357-68. 30- Tiossi R, Lin L, Rodrigues RC, Heo YC, Conrad HJ, Mattos MG, et al. Digital image correlation analysis of the load transfer by implant-supported restorations. J Biomech. 2011;44:1008-13. 31- Zitzman NU, Krastl G, Hecker H, Walter C, Waltimo T, Weiger R. Strategic considerations in treatment planning: deciding when to treat, extract, or replace a questionable tooth. J Prosthet Dent. 2007;104:80-91. 